\title{
ORIGINAL ARTICLE \\ Estimating the global incidence of traumatic spinal cord injury
}

\author{
M Fitzharris ${ }^{1}$, RA Cripps ${ }^{2}$ and BB Lee $\mathrm{e}^{3,4}$
}

Study design: Population modelling-forecasting.

Objectives: To estimate the global incidence of traumatic spinal cord injury (TSCI).

Setting: An initiative of the International Spinal Cord Society (ISCoS) Prevention Committee.

Methods: Regression techniques were used to derive regional and global estimates of TSCl incidence. Using the findings of 31 published studies, a regression model was fitted using a known number of TSCI cases as the dependent variable and the population at risk as the single independent variable. In the process of deriving TSCl incidence, an alternative TSCI model was specified in an attempt to arrive at an optimal way of estimating the global incidence of TSCI.

Results: The global incidence of TSCl was estimated to be 23 cases per 1000000 persons in 2007 (179312 cases per annum). World Health Organization's regional results are provided.

Discussion: Understanding the incidence of $\mathrm{TSCl}$ is important for health service planning and for the determination of injury prevention priorities. In the absence of high-quality epidemiological studies of TSCI in each country, the estimation of TSCI obtained through population modelling can be used to overcome known deficits in global spinal cord injury (SCl) data. The incidence of TSCl is context specific, and an alternative regression model demonstrated how TSCI incidence estimates could be improved with additional data. The results highlight the need for data standardisation and comprehensive reporting of national level TSCI data. A step-wise approach from the collation of conventional epidemiological data through to population modelling is suggested.

Spinal Cord (2014) 52, 117-122; doi:10.1038/sc.2013.135; published online 10 December 2013

Keywords: traumatic spinal cord injury; epidemiology; incidence; population modelling; forecasting

\section{BACKGROUND}

Global maps have been developed along with an online data repository to present and manage information necessary to inform spinal cord injury (SCI) prevention programmes. ${ }^{1}$ The global maps resource has been developed for the International Spinal Cord Society (ISCoS) Prevention Committee and the wider ISCoS membership for the purpose of defining injury prevention priorities.

The first iteration of the traumatic SCI (TSCI), the global map developed by Cripps et al., ${ }^{1}$ published in Spinal Cord, utilised the published literature as the basis of representing the incidence of TSCI. The TSCI incidence estimates used were those obtained through population-based observation studies, with particular emphasis given to studies using prospective SCI registries and population-basedhealth data systems. Incidence data were presented as 'green zone' data when drawn from the registry and as population-based data sources or 'yellow zone' data when partial coverage of a country or World Health Organization (WHO) region was available. When no data were available for a WHO region, the term 'red zone' was used. Indeed, Cripps et al. stated that 'incidence data was comparable only for regions in North America (39 per million), Western Europe (15 per million) and Australia (16 per million)', but notably, only Australia was attributed the 'green zone' status. Using a large number of studies, Cripps et al. were able to describe in terms of percentage the external cause of injury; however, owing to insufficient incidence data, they were unable to provide a TSCI incidence estimate for 11 of the 14 WHO regions.

Following their literature review, Cripps et al. ${ }^{1}$ noted that a fundamental difficulty in arriving at comparable TSCI incidence rates was the lack of standardisation in outcome measures and measurement practices. In addition, the absence of research activity specific to SCI in a significant number of countries limits the derivation of TSCI incidence and prevalence rates for a number of WHO regions. Given the cost of establishing and maintaining a trauma registry and population-based health data systems, ${ }^{2}$ it is thus unsurprising that a global estimate of TSCI incidence has yet to be derived.

In the absence of comprehensive uniform global injury data, population modelling has been used to derive regional and global estimates of injury incidence, and associated mortality and morbidity. Examples include cause of death models as part of the global burden of disease project, ${ }^{3,4}$ as well as for specific mechanisms of injury, such as road traffic crashes, ${ }^{5}$ or for particular age groups of interest, such as child injury mortality. ${ }^{6}$ The estimation of injury incidence generally relies upon survey data of key respondent groups, snap shots of vital registration data and/or studies of hospital presentation and admission rates.

\footnotetext{
${ }^{1}$ Monash Injury Research Institute, Monash University, Melbourne, Victoria, Australia; ${ }^{2}$ School of Medicine at Flinders University, Prevention, Promotion and Primary Health Care Cluster, Adelaide, South Australia, Australia; ${ }^{3}$ Spinal Medicine Department, Prince of Wales Hospital, Sydney, New South Wales, Australia and ${ }^{4}$ School of Public Health, University of New South Wales, Sydney, New South Wales, Australia

Correspondence: Dr M Fitzharris, Monash Injury Research Institute, Building 70, Monash University, Melbourne, Victoria 3800 , Australia.

E-mail: michael.fitzharris@monash.edu
}

Received 5 March 2012; revised 14 October 2013; accepted 14 October 2013; published online 10 December 2013 
Given the large gaps in knowledge and consequent inability to establish a global estimate of TSCI incidence based on existing health data systems, population modelling methods can be used to estimate the incidence of TSCI based on observed relationships between TSCI and population-or any other factor (for example, number of registered motor vehicles; alcohol sales and so on) in locations where TSCI incidence studies have been conducted. In the absence of observed TSCI incidence data, estimated TSCI incidence rates based on population modelling permit a broader level of understanding of the magnitude of TSCI and can be used to prioritise injury prevention programs and develop effective health policy. This is particularly important given the significant mortality and morbidity associated with SCI.

This paper introduces techniques to derive TSCI incidence using available data. This approach permits the estimation of TSCI in regions where Cripps et al. were unable to establish a TSCI incidence rate (that is, 'red zone' regions). Hence, the aim of this paper is to estimate the global incidence of TSCI, and in doing so provide TSCI incidence rates for all WHO regions.

\section{MATERIALS AND METHODS}

Using past studies the relationship between observed TSCI and population can be determined using linear regression methods. ${ }^{7}$ The incidence values of TSCI were obtained from 31 research papers from the global data repository described in Cripps et al., which described the incidence rate and the proportion with tetraplegia and paraplegia. ${ }^{1,8-38}$ Where the population at risk (that is, number of people in the country or the study catchment area) was not reported, the stated number of TSCI cases combined with the incidence rate was used to derive the population 'at risk'. The 31 studies were those conducted from 1990 onwards, however, exception was made for the two studies $^{28,30}$ as they were the only two studies from Sub-Saharan Africa, both of which contained incidence data commencing in 1988. The 31 studies were set:Japan (observed TSCI incidence rate: 40.2 per million persons ${ }^{32}$ ), China $\left(23.7^{24} ; 60.6^{22}\right.$, Vietnam $\left(13.9^{38}\right)$, Australia $\left(14.9^{13} ; 14.5^{25}\right)$, Estonia $\left(27.9^{31}\right)$, Russia $\left(29.7^{33} ; 44^{20}\right)$, France $\left(19.4^{8}\right)$, Greece $\left(33.6^{14}\right)$, Ireland $\left(13.1^{26}\right)$, Italy $\left(20^{27} ; 14.3^{11}\right)$, The Netherlands $\left(7.5^{35}\right)$, Iran $\left(62.2^{29}\right)$, Turkey $\left(21.1^{19} ; 16.9^{18}\right.$; $\left.12.1^{17}\right)$, Canada $\left(35^{30} ; 52.5^{15} ; 24^{12} ; 38^{16} ; 42.4^{28}\right)$, the USA $\left(40^{23} ; 83^{37} ; 27.1^{10}\right.$ $\left.77^{34} ; 56^{9}\right)$, South Africa $\left(13.9^{36}\right)$ and Zimbabwe $\left(11.7^{21}\right)$. The population for each of the 31 studies was either reported or calculated from information by the authors of this paper.

Using the data from the 31 research papers noted above, a linear regression model was fitted using the known number of TSCI cases as the dependent variable and the population at risk as the single independent variable (see Box 1; known as the population-only model). Linear regression assumes that the relationship between the dependent variable (TSCI) and the independent

\section{Box 1 Formula for the estimation of $\mathrm{TSCl}$ used for each country}

SCIest $=$ constant $+\beta 1 \times($ population 1$)+\beta 2 \times($ population 2$)$ where

$$
\begin{aligned}
& \beta 1=3596.208(95 \% \mathrm{CL}: 3292.678 \text { to } 3899.737) \dagger \\
& \beta 2=-2130.132(95 \% \mathrm{CL}:-2433.23 \text { to }-1827.035)
\end{aligned}
$$$$
\text { constant }=373.4508(95 \% \text { CL : } 304.2426 \text { to } 442.659) \dagger
$$$$
\text { And where : population } 1=X^{2}-0.0381500612
$$$$
\text { population } 2=X^{2} * \ln (X)+0.0623033975
$$$$
\text { (where : } X=\text { pop } / 100000000)
$$

Note: $\dagger, P \leqslant 0.05$ variable (population at risk) is linear; however, this was shown not to be the case by model testing using fractional polynomials. Hence, the use of fractional polynomials improved the 'fit' of the model and in this instance population values were expressed as two separate yet additive terms; the end result is that specifying population as two additive terms better explains the observed TSCI incidence in each of the 31 studies (refer Box 1). ${ }^{8-38}$ The adjusted- $r^{2}$ for the model was $99 \%$ and the model was highly statistically significant $(P<0.001)$. Analysis was performed in STATA (version 12/MP; Statacorp, Austin, TX, USA).

Using the regression equation in Box 1, an estimate of TSCI can be made for each country using reported population. In total, population data was known for 178 countries with 2007 population data being used. ${ }^{5}$ For example, Australia had a population of 20743179 in 2007, and by means of substitution into the formula presented in Box 1, the TSCI incidence was estimated to be 402 , with the $95 \%$ confidence intervals (CIs) stating that this could range from 333 to 472 ; this translates to a TSCI incidence rate of 19.4 per million persons (95\% CI: 16.1-22.7). The same process was undertaken for each country where population was known, with the known population value being represented as ' $X$ ' in equation (7) to then obtain values for populationl (equation 5) and population2 (equation 6). The two values derived using are then substituted in equation (1) with values presented in equations (2-4) to obtain the TSCI estimate for that individual country. The only parameter to change in the estimation of TSCI is the population of the country in question. This step was performed in MS Excel (Microsoft, Redmond, WA, USA) following estimation of the regression equation in STATA as described above.

\section{Alternative model specifications}

It is accepted thatalthough population can be used as the basis of estimation in its most basic form, other variables have an important role in the incidence of injury. At the outset it was anticipated that using a more complex estimation model with a broader set of development and economic indicators would yield more robust TSCI estimates.

The modelling process commenced using population and economic indicator data gathered for 178 countries cited in the WHO global status report on road safety. ${ }^{5}$ As per the World Bank classification, based on the gross national income per capita (GNI, Atlas method $\left.{ }^{39}\right)$, 42 jurisdictions were classified as high-income countries ( $\geqslant \$ 11456$, HIC), 91 were middle-income countries (\$936-11455, MIC) and 45 were low-income countries $(\leqslant \$ 935$, LIC). These 178 jurisdictions represented $91.2 \%$ of all member and associate member states (refer Table 2, p. 10 in World Health Organization. Global status report on road safety: time for action ${ }^{5}$ ); the 19 non-participating countries and territories comprise $1.9 \%$ of the global population.

For each of the 178 countries, a range of economic and development indicators using various sources were linked to the WHO population and income status variables. These additional variables included unemployment rate, urbanisation (of the population) ${ }^{40,41}$ and the United Nations Human Development Index (HDI). ${ }^{42}$ The HDI is a comprehensive development composite index that incorporates life expectancy, education, income, infrastructure and associated measures of inequality, measures of environmental sustainability, well being and happiness, demographic trends, health, physical and media infrastructure and access to information and communication technology. The HDI was available for 157 countries for the 2005 calendar year, whereas all other values related to 2007.

The alternative regression model used population, income, urbanisation, unemployment and the United Nation's HDI, rather than population alone (Box 1), to estimate the incidence of TSCI for each country and is presented in Box 2 (that is, alternative model). The adjusted $-r^{2}$ for the model was $97 \%$ and the model was highly statistically significant $(P<0.001)$. Analysis was conducted in STATA. The application of the formula is the same as for Box 1 .

\section{RESULTS}

\section{Population-only model}

Using the population-based regression model, the calculation of a TSCI incidence estimate was able to be performed for 131 of the 178 countries (74\%) (Appendix Table 1 for detail on each country in Supplementary Material). 


\section{Box 2 Formula for the estimation of $\mathrm{TSCl}$ (alternative model)}

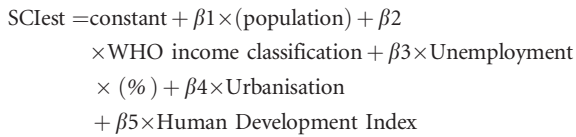

where:

$$
\begin{aligned}
\beta 1= & 0.0000401(95 \% \mathrm{CL}: 0.0000385 \text { to } 0.0000416) \dagger \\
\beta 2= & \text { Income level 1 (middle) }=762.1305(95 \% \mathrm{CL}: \\
& -53.48418 \text { to } 1577.745) \\
& \text { Income level } 2 \text { (high) }=495.0312(95 \% \mathrm{CL}:-665.669 \text { tol } 655.753)
\end{aligned}
$$

$\beta 3=$ Unemploymentpercent

$=20.32637(95 \% \mathrm{CL}: 0.2088747$ to 40.44387$) \dagger$

$\beta 4=$ Urbanisation $=-17.34702(95 \% \mathrm{CL}:-31.53629$ to -3.157744$) \dagger$

$\beta 5=$ Human Development Index

$=4033.327(95 \%$ CL $:-275.043$ to 8341.696$)$

constant $=-2485.609(95 \% \mathrm{CL}:-5651.86$ to 680.6419$)$

Note: $\dagger, P \leqslant 0.05$

was 25.8 TSCI incident cases per million persons. Owing to the large number of countriesthat an estimate could not be derived, aggregated summary statistics by WHO region as per Table 1 are not presented. For thoroughness, the TSCI incidence estimate (number of cases, rate) is presented in Appendix Table 1 (Supplementary Material).

\section{DISCUSSION}

Using population modelling, and based on the observed relationships between TSCI and the population at risk in each of the studies cited in Materials and Methods, it was possible to present a model that estimates TSCI for 131 countries. The derived TSCI estimates represent the expected number of TSCI cases given the observed relationship between TSCI and the population reported in research studies. It was the case though that estimates for 47 countries in the population-only model were unsatisfactory. This appeared to affect small island countries in particular, and this highlights that the model is only as robust as the studies upon which it is based, in this case, 31 studies, none of which were undertaken in small populations.

A most likely explanation for this limitation is that the TSCI population-only model used known incidence and population data from only 31 studies that were set in only 17 countries, with only 10 representing national estimates. None of the studies were set in small island populations, only 2 in low-income countries, 10 in middleincome countries and 19 in high-income countries with Australia, Canada and the USAcollectively accounting for 12 original studies. The need for additional population-based TSCI across a broad range of countries is clear.

The accuracy of the TSCI incidence rates derived by the population model can be assessed by examining the estimated TSCI incidence and the reported TSCI incidence in the original studies. By way of example, the original Australian studies reported the TSCI incidence to be $14.5^{25}$ and $14.9^{13}$ cases per million persons, whereas the population-based model estimated the incidence to be 19.4 per million persons (95\% CI: 16.1-22.7). For the USA, the National Spinal Cord Injury Statistical Center (NSCISC) ${ }^{23}$ reported a TSCI incidence of 40 per million persons, whereas the population-based model estimates the incidence of TSCI to be 37.5 per million persons (95\% CI: 17.6-56.4 TSCI cases per million persons).

It is noteworthy that the TSCI estimates for Australia given by the two models was similar (population-only model: 402 TSCI cases, rate: 19.4 per million persons; alternative model: 421 TSCI cases, rate: 20.3 per million persons). It is likely that this result reflects the strength of the input data, particularly as 2 of the 31 studies from which the relationship between TSCI incidence and population are reported were population-based Australian studies. Similarly, the USA TSCI incidence estimate 95\% CI range captures the actual TSCI incidence reported by three of the five USA studies, ${ }^{9,10,23}$ with the actual incidence being higher for two (Alaska (77 per million persons); ${ }^{34}$ Mississippi (83 per million persons) ${ }^{37}$ ) studies; importantly, the average TSCI incidence reported by the five studies was 56.6 per million persons, approximately equivalent to the upper 95th\% CI.

The above highlights the point that the strength of the TSCI estimations relies upon the input data in determining the relationship between actual incidence and the known population. That the TSCI incidence estimate for the USA was close to that reported by the NSCISC national TSCI incidence rate is unsurprising as the population model reflects the average occurrence. Where the actual data is reported from a sub-national location, such as a specific city or region, higher or lower incidence rates than the national estimate would be expected. In such cases, TSCI incidence rates would be dependent on-and more senstive to, the nature of the population at

million persons (model 2), whereas the comparable incidence rate using the same 103 countries by the population-only model (Box 1) 
Table 1 Traumatic $\mathrm{SCl}$ incidence estimates by WHO region

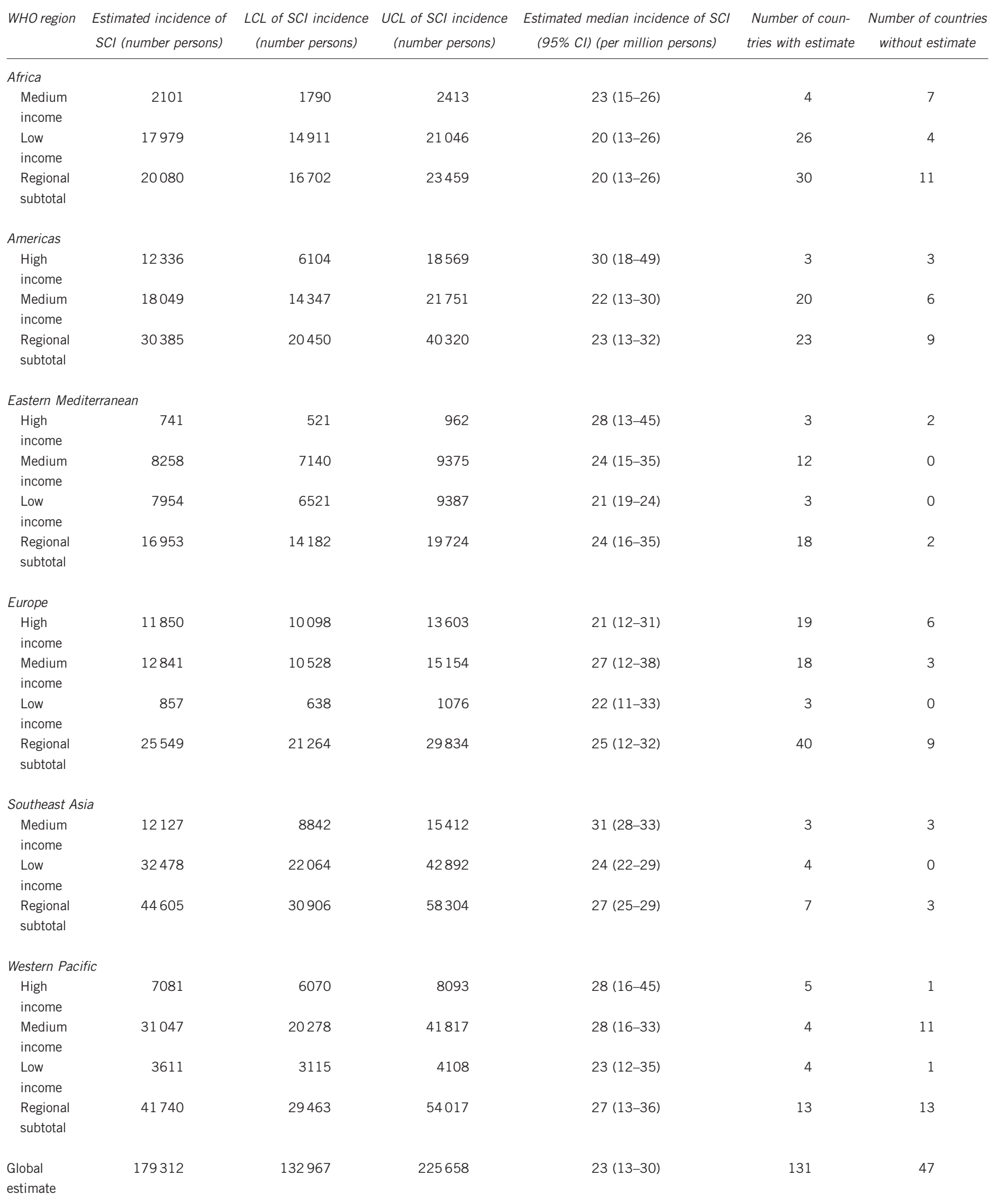

Abbreviations: LCL, lower confidence level; SCI, spinal cord injury; UCL, upper confidence level. 
risk, manifested in the nature of the economy, local industry and other contexual factors.

An alternative TSCI population incidence model was developed with the expectation that additional variables would improve the model and produce TSCI incident numbers (and rates) more specific to the prevailing economic context apparent in each country. The alternative model included a broader range of economic and development indicators including unemployment, income status (high, middle and low), HDI and the percentage of the population residing in an urban population. Although conceptually useful, an estimate of TSCI could not be obtained for 73 countries (excluding China and India). This was the result of one or more factors such as unemployment, urbanisation or the HDI value being unknown.

The two estimation models produced different TSCI incident rates (model 1: 25.8 per million persons; model 2: 34.4 per million persons), with this difference being driven in large part by the significantly higher TSCI estimate for the USA, this being 4.9 times higher (that is, 56199 TSCI cases in model 2 (rate, 183 per million) vs 11468 TSCI cases (rate, 37.5 per million) in model 1). The alternative model resulted on average a $33 \%$ higher TSCI incidence than the population-only model, and excluding the USA that reduced nominally to $29 \%$ more TSCI cases. The inclusion of additional socioeconomic variables in model 2 adds complexity to the estimation model, and then relies on the relationship between these and the original 31 studies upon which the regression equation is based. As per the population model, this small number of studies (31) formed the basis of the relationship between population, and the limitation of this is noted above. Put simply, the small number of studies constrains the accuracy of the TSCI estimates and this represents a limitation to the current analysis; indeed, only a larger number of epidemiological field-work studies would overcome this limitation.

Despite the poorer performance of the alternative TSCI estimation model, the current method of basing TSCI incident estimates on the simple regression relationship between known TSCI and population is also not without limitations, particularly given the complex nature of SCI. Recognition of this led to the development of a more sophisticated model that sought to account for a range of economic and development indicators, although the lack of complete global coverage for these additional indicators meant that the incidence of TSCI was estimated for fewer countries. The analysis reported here highlights the ongoing need for the further development of the alternative model. Future work will be focussed on refining the current method by examining a broad range of variables (for example, population age distribution, alcohol sales, fuel consumption) that could influence the incidence of TSCI injury in society. This work is, however, wholly dependent upon new studies being published that examine the epidemiology of SCI in the field, as this will permit the TSCI regression model to be more robust. Finally, the source data inputs in the regression models must be matched to a single calendar year (for example, 2007 as used here) as the basis of estimations. Although more recent input data were available for a number of independent variables, the 2007 calendar year was used as the full range of source data was available at the time of analysis. It does however remain important that revised estimates of TSCI are published regularly.

\section{Integration of these estimation methods within the ISCoS prevention committee global mapping project}

The initial global mapping work by Cripps et al. ${ }^{1}$ highlighted the paucity of available TSCI incidence data. By representing TSCI incidence in a graphical manner it was readily apparent that significant gaps exist in our understanding of the global incidence of TSCI. These gaps were presented as 'red zones' in the original global mapping work; ${ }^{1}$ however, using the estimates of TSCI incidence reported here, these 'gaps' can be closed. The estimation of TSCI incidence and associated incidence rates as reported here form an important part of expanding the reach of the ISCoS global mapping project, particularly in light of the relatively few populationbased TSCI studies undertaken globally.

On the basis of the work undertaken here, there is a clear need for additional studies to be undertaken. Although recognising the significant financial costs and resource requirements in establishing population-based surveillance systems, it is recommended that standardised collection and reporting of TSCI data be adhered to. In lieu of this, it can stated that the ISCoS Prevention Committee has developed and implemented the following step-wise approach to mapping global data:

1. Standardised conventional methods of evaluating and mapping existing published data in order to identify data deficits within an area.

2. Encourage the use of the ISCoS core data $\operatorname{set}^{43}$ and the International Classification of External Causes of Injury inherent in the ISCoS prevention committee's data collection tool, ${ }^{44}$ the purpose of which is to provide a platform for a coordinated TSCI prevention programme. It is expected that these strategies will assist ISCoS members in facilitating the exploration, extrapolation, implementation and evaluation of appropriate prevention strategies.

3. Where underlying (that is, input) data are available and robust, use population modelling to better estimate SCI incident data for each of the WHO global regions, ${ }^{4}$ so as to provide improved global statistics for incidence. ${ }^{45}$

The analysis undertaken here was purposely designed to estimate the incidence of TSCI. There is an opportunity to use the same methods to derive estimates of non-TSCI (NTSCI). At present though, it can be stated that there are insufficient source data to derive an estimating regression model for NTSCI. Consequently, no global estimate of NTSCI can be made at this time. It is notable, however, that data extrapolation is being used to estimate NTSCI prevalence between two socioeconomically similar countries (Canada and Australia), ${ }^{46}$ which it is expected will shed light on the extent of morbidity associated with NTSCI. Furthermore, the establishment of NTSCI data standards in this area currently in draft form (http:// www.iscos.org.uk/page.php?content $=20$ ) and the ISCoS global data repository will assist in improving NTSCI data to a level where the derivation of global NTSCI estimates are possible using the regression techniques described here in relation to TSCI.

\section{CONCLUSION}

Overall, using published research incidence data, population data and population modelling procedures, an estimate of TSCI incidence was derived for 131 of the 178 countries. This information is useful in filling known gaps in our understanding of the incidence of TSCI, and is of value in guiding injury prevention priorities and health service provision. The fact that the estimation of TSCI by population modelling was necessary reinforces the need for TSCI incidence data derived from original and well-designed epidemiological studies. It is recommended that future studies adopt standardised data collection instruments and reporting standards. 


\section{DATA ARCHIVING}

There were no data to deposit.

\section{CONFLICT OF INTEREST}

The authors declare no conflict of interest.

1 Cripps RA, Lee BB, Wing P, Weerts E, Mackay J et al. A global map for traumatic spinal cord injury epidemiology: towards a living data repository for injury prevention. Spinal Cord 2011; 49: 493-501.

2 Fitzharris M, Yu J, Hammond N, Taylor C, Wu Y, Finfer S et al. Injury in China: a systematic review of injury surveillance studies conducted in Chinese hospital emergency departments. BMC Emerg Med 2011; 11: 18

3 Murray CJL, Lopez A. The global burden of disease: a comprehensive assessment of mortality and disability from diseases, injuries and risk factors in 1990 and projected to 2020 (Global Burden of Disease and Injury Series Vol. I). Harvard School of Public Health: Boston, MA, USA, 1996.

4 World Health Organization. Global burden of disease (GBD), (death and daly estimates for 2002 by cause for WHO member states, version 3 estimates). World Health Organisation: Geneva, Switzerland. www.who.int/entity/healthinfo/statistics/ bodgbddeathdalyestimates.xls. accessed 23 February 2012, 2004

5 World Health Organization. Global Status Report on Road Safety: Time for Action. World Health Organization: Geneva, Switzerland. http://www.who.int/violence injury prevention/road_safety_status/2009/en/. accessed 23 February 2012, 2009

6 Peden M, Oyegbite K, Ozanne-Smith JE, Hyder A, Branche CM, Fazlur Rahman A et al. World Report on Child Injury Prevention. World Health Organisation: Geneva, Switzerland. http://www.who.int/violence_injury_prevention/child/injury/world_report/. accessed 23 February 2012, 2008

7 Vittinghoff E, Glidden DV, Shiboski SC, McCulloch CE. Regression Methods in Biostatistics: Linear, Logistic, Survival and Repeated Measures Models. Springer: New York, NY, USA, 2005.

8 Albert T, Ravaud JFTetrafigap group. Rehabilitation of spinal cord injury in France: a nationwide multicentre study of incidence and regional disparities. Spinal Cord 2005; 43: 357-365

9 Buechner JS, Speare MC, Fontes J. Hospitalizations for spinal cord injuries, 1994-1998. MedHealth R/ 2000; 83: 92-93.

10 Burke D, Linden R, Zhang Y, Maiste A, Shields C. Incidence rates and populations at risk for spinal cord injury: a regional study. Spinal Cord 2001; 39: 274-278.

11 Caldana L, Lucca L. Epidemiological remarks on traumatic spinal cord injuries and non-traumatic spinal cord diseases in Veneto 1994-1995. Eur Med Phys 1998; 34: 159-168.

12 Couris CM, Guilcher SJ, Munce SE, Fung K, Craven BC, Verrier M et al. Characteristics of adults with incident traumatic spinal cord injury in Ontario, Canada. Spinal Cord 2010; 48: 39-44.

13 Cripps R. Spinal Cord Injury Australia, 2006-07. In: Injury Research and Statistics Series Number 48. Cat. no. INJCAT 119 AlHW: Adelaide, SA, Australia, 2008.

14 Divanoglou A, Levi R. Incidence of traumatic spinal cord injury in Thessaloniki, Greece and Stockholm, Sweden: a prospective population-based study. Spinal Cord 2009; 47 $1-6$

15 Dryden D, Saunders L, Rowe B, May L, Yiannakoulias N, Svenson L et al. The epidemiology of traumatic spinal cord injury in Alberta, Canada. Can J of Neurol SCi 2003; 30: 113-121.

16 Furlan JC, Bracken MB, Fehlings MG. Is age a key determinant of mortality and neurological outcome after acute traumatic spinal cord injury? Neurobiol Aging 2010; 31: 434-446.

17 Gur A, Kemaloglu MS, Cevik R, Sarac AJ, Nas K, Kapukaya A et al. Characteristics of traumatic spinal cord injuries in south-eastern Anatolia, Turkey: a comparative approach to 10 years' experience. Int J Rehabil Res 2005; 28: 57-62.

18 Karamehmetoglu S, Nas K, Karacan I, Sarac A, Koyuncu H, Ataoglu S et al. Traumatic spinal cord injuries in Southeast Turkey: an epidemiological study. Spinal Cord 1997; 35: 531-533.

19 Karamehmetoglu S, Unal S, Karacan I, Yilmaz H, Togay H, Ertekin M et al. Traumatic spinal cord injuries in Istanbul, Turkey. An epidemiological study. Paraplegia 1995; 33: 469-471.
20 Kondakov EN, Simonova IA, Poliakov IV. The epidemiology of injuries to the spine and spinal cord in Saint Petersburg. Z Vopr Neirokhir Im N N Burdenko 2002; 2 $50-53$.

21 Levy LF, Makarawo S, Madzivire D, Bhebhe E, Verbeek N, Parry O. Problems, struggles and some success with spinal cord injury in Zimbabwe. Spinal Cord 1998; 36 213-218.

22 Li J, Liu G, Zheng Y, Hao C, Zhang Y, Wei B et al. The epidemiological survey of acute traumatic spinal cord injury (ATSCI) of 2002 in Beijing municipality. Spinal Cord 2011; 49: 777-782.

23 National Spinal Cord Injury Statistical Center. Spinal cord injury. Facts and figures at a glance. J Spinal Cord Med 2005; 28: 379-380.

24 Ning G-Z, Yu T-Q, Feng S-Q, Zhou X-H, Ban D-X, Liu Y et al. Epidemiology of traumatic spinal cord injury in Tianjin, China. Spinal Cord 2011; 49: 386-390.

25 O'Connor P. Incidence and patterns of spinal cord injury in Australia. Accid Anal Prev 2002; 34: 405-415

26 O'Connor RJ, Murray PC. Review of spinal cord injuries in Ireland. Spinal Cord 2006; 44: 445-448.

27 Pagliacci MC, Celani MG, Zampolini M, Spizzichino L, Franceschini M, Baratta S et al. An Italian survey of traumatic spinal cord injury. The Gruppo Italiano Studio Epidemiologico Mielolesioni Study. Arch Phys Med Rehabil 2003; 84: 1266-1275.

28 Pickett GE, Campos-Benitez M, Keller JL, Duggal N. Epidemiology of traumatic spinal cord injury in Canada. Spine 2006; 31: 799-805.

29 Rahimi-Movaghar V, Moradi-Lakeh M, Rasouli M, Vaccaro A. Burden of spinal cord injury in Tehran, Iran. Spinal Cord 2010; 48: 492-497.

30 Rick Hansen Spinal Cord Injury Register. Spinal Cord Injury Facts and Statistics: Canada 2006.

31 Sabre L, Linnamagi U, Derrik G, Rekand T, Asser T, Korv J. Traumatic spinal cord injuries in Estonia from 2003 to 2007. In Program and Abstract: 48th ISCoS Annual Scientific Meeting 2009. University of Tartu: Florence, Italy, 2009.

32 Shingu $\mathrm{H}$, Ohama M, Ikata T, Katoh S, Akatsu T. A nationwide epidemiological survey of spinal cord injuries in Japan from January 1990 to December 1992. Paraplegia 1995; 33: 183-188.

33 Silberstein B, Rabinovich S. Epidemiology of spinal cord injuries in Novosibirsk, Russia. Paraplegia 1995; 33: 322-325.

34 Surkin J, Gilbert B, Harkley H, Sniezek J, Currier M. Spinal cord injury in Mississippi. Findings and evaluation, 1992-1994. Spine 2000; 25: 716-721.

35 van Asbeck F, Post M, Pangalila R. An epidemiological description of spinal cord injuries in The Netherlands in 1994. Spinal Cord 2000; 38: 420-424.

36 Velmahos GC, Degiannis E, Hart K, Souter I, Saadia R. Changing profiles in spinal cord injuries and risk factors influencing recovery after penetrating injuries. J Trauma 1995 38: 334-337.

37 Warren S, Moore M, Johnson M. Traumatic head and spinal cord injuries in Alaska (1991-1993). Alaska Med 1995; 37: 11-19.

38 Weerts E. Prevention of spinal cord injury accidents. What does it mean? How can I avoid it? How can I help?: Hanoi, Vietnam, 2008.

39 The World Bank. GNI per capita 2007: Atlas method and PPP. The World Bank: Washington, DC, USA. http://data.worldbank.org/indicator. accessed 23 February 2012, 2007

40 Central Intelligence Agency. The World Factbook, 2007. Washington, DC, USA https://www.cia.gov/library/publications/download/download-2007/index.html. accessed 23 February 20122007

41 Central Intelligence Agency. The World Factbook, 2008. Washington, DC, USA https://www.cia.gov/library/publications/download/download-2008/index.html. accessed 23 February 20122008

42 The UNDP Human Development Report Office. Human development report 2010, the real-wealth of nations: pathways to human development. United Nations Development Programme: New York, NY, USA. http://hdr.undp.org/en/media/HDR_2010_EN_Complete_reprint.pdf. accessed 23 February 2012, 2010

43 DeVivo M, Bierring-Sorensen F, Charlifue S, Noonan V, Post M, Stripling T et al. International spinal cord injury core data set. Spinal Cord 2006; 44: 535-540.

44 Lee B, Cripps RA, Woodman RJ, Biering-Sorensen F, Wing P, Campbell R et al. Development of an international spinal injury prevention module: application of the the international classification of external cause of injury to spinal cord injury. Spinal Cord 2010; 48: 498-503

45 Lee B, Cripps RA, Fitzharris M, Wing PC. The global map for traumatic spinal cord injury epidemiology: update 2011, global incidence rate. Spinal Cord 2014; 52: $110-116$.

46 Noonan V, Fingas M, Farry A, Baxter D, Singh A, Fehlings M et al. The incidence and prevalence of spinal cord injury in Canada: a national perspective. Neuroepidemiology 2012; 38: 219-226.

Supplementary Information accompanies this paper on the Spinal Cord website (http://www.nature.com/sc) 